\title{
Aprendizagem da docência na formação inicial de professores: estudar para ensinar matemática
}

\author{
Teaching of learning in initial teacher education: need and \\ sense of studying to teach mathematics
}

\author{
Simone POZEBON ${ }^{1}$ \\ Anemari Roesler Luersen Vieira LOPES²
}

\begin{abstract}
Resumo
Este artigo apresenta resultados de uma pesquisa com acadêmicos de Licenciatura em Matemática e Pedagogia em um projeto desenvolvido com alunos do Ensino Fundamental em uma escola de rede pública estadual do Rio Grande do Sul. Com o objetivo de discutir sobre a aprendizagem da docência desses futuros professores, coletaram-se os dados a partir de gravaçóes de áudio e vídeo, analisando-os por meio de seleçáo de episódios. A análise permitiu identificar indícios reveladores de aprendizagem da docência em dois aspectos principais: a necessidade dos futuros professores de estudar o conteúdo a ser ensinado e o sentido atribuído por eles a essa ação.
\end{abstract}

Palavras-chave: Formação de Professores. Educação Matemática nos Anos Iniciais. Atividade Orientadora de Ensino.
Abstract

This article presents results of a survey with students of Graduation in Mathematics and Pedagogy in a project developed with students in the early years of primary education in a public state school in Rio Grande do Sul. Aiming to discuss the teaching training of these future teachers, we collected the data from audio and video recordings, being the systematization movement performed by selection of episodes. This analysis revealed telltale evidence of teaching learning in two main aspects: the need for future teachers to study on the content to be taught and the meaning attributed by them to this action.

Keywords: Teachers training. Mathematica education in the early years. Teaching guiding activity.

1 Doutoranda em Educação do Programa de Pós-Graduação em Educação da Universidade Federal de Santa Maria (UFSM). Licenciada em Matemática e Mestre em Educação pela mesma Instituição. Av. Roraima, no 1000, Bairro Camobi, Santa Maria/RS. CEP: 97105-900. E-mail: <spozebon@gmail. com>.

2 Doutora em Educação (FE-USP). Professora Adjunta do Departamento de Metodologia do Ensino e do Programa de Pós-Graduação em Educação e do Programa de Pós-Graduação em Educação Matemática e Ensino de Física da Universidade Federal de Santa Maria (UFSM). Av. Roraima, no 1000, Bairro Camobi, Santa Maria/RS. CEP: 97105-900. E-mail: <anemari.lopes@gmail.com>.

R. Educ. Públ.

Cuiabá

v. 28 n. 67

p. $219-238$ jan./abr. 2019 


\section{Introdução}

Em uma obra clássica do início do período em que se acentuaram as discussóes sobre Educação Matemática no Brasil, Ubiratan D’Ambrosio (1986) escreveu que as formas de ensino do conhecimento matemático contribuem para que essa disciplina seja vista como complexa, o que gera dificuldades de aprendizagem e altos índices de reprovação. Destacou, ainda, que os problemas não se referem apenas às dificuldades dos alunos: implicam também dificuldades encontradas pelos professores, que, muitas vezes, não conseguem aprofundar-se nos conhecimentos necessários para a sua prática docente. Passadas quase três décadas dessa afirmação, embora não possamos negar que tenham ocorrido muitos avanços, a mesma preocupaçáo de D`Ambrosio continua mobilizando professores e pesquisadores, que buscam tanto compreender esse processo quanto desenvolver açóes que universalizem a aprendizagem da Matemática.

Encontramo-nos nesse contexto como professoras de cursos de licenciatura e pesquisadoras que participam de um projeto interinstitucional ${ }^{3}$ (financiado pelo OBEDUC/CAPES) que investiga princípios e práticas da organização do ensino de Matemática para os anos iniciais do Ensino Fundamental. Esse projeto é desenvolvido por quatro instituiçôes de diferentes regióes do Brasil, e estão vinculadas a ele diversas ações e investigaçóes, porém, especificamente neste artigo, traremos resultados de uma pesquisa desenvolvida pela primeira autora e orientada pela segunda, que versou sobre formação inicial de professores.

A organização do ensino tem um papel fundamental para os professores que ensinam Matemática e, diante disso, referenciamo-nos teórica e metodologicamente na Atividade Orientadora de Ensino (AOE) (MOURA, 1996, 2001), uma proposta para o trabalho do professor embasada na Teoria Histórico-Cultural e também uma possibilidade de realizar a atividade educativa, tendo como base o conhecimento produzido sobre os processos humanos de construção de conhecimento (MOURA et al., 2010).

Amparadas por esses pressupostos, defendemos a necessidade e a possibilidade de organizar o ensino visando à apropriação de conhecimentos que promovam o desenvolvimento das funçóes psíquicas superiores dos educandos. Assim, compete ao professor que ensina Matemática propor situaçóes desencadeadoras

3 Projeto "Educaçấo Matemática nos Anos Iniciais do Ensino Fundamental: princípios e práticas da organização do ensino", OBEDUC/PPOE, desenvolvido em parceria com a Universidade de São Paulo, campus São Paulo e campus Ribeirão Preto, a Universidade Federal de Santa Maria e a Universidade Federal de Goiás. 
de aprendizagem aos alunos, levando em consideração os conteúdos e os conceitos a serem trabalhados, de forma que essas situaçóes possam mobilizar os docentes em direção à concretização dos objetos próprios do ensino e da aprendizagem.

O lócus da investigação aqui apresentada refere-se a um projeto - vinculado ao citado anteriormente - que acontece em parceria com escolas da rede estadual de ensino do Rio Grande do Sul, em que estudantes dos cursos de Licenciatura em Matemática e Pedagogia se reúnem semanalmente para estudar, planejar, desenvolver e avaliar atividades de ensino de Matemática. Com o objetivo de discutir sobre a aprendizagem da docência de futuros professores, reportarnos-emos à organização de uma dessas atividades de ensino, que versava sobre grandezas e medidas e foi desenvolvida com alunos do terceiro ano do Ensino Fundamental. Mais especificamente, direcionaremos nosso olhar ao momento de estudo, que visa subsidiar teoricamente o trabalho a ser realizado, no que diz respeito ao conhecimento matemático envolvido nas atividades organizadas.

Para situar o leitor de onde falamos, inicialmente traremos de forma breve os pressupostos teóricos que fundamentaram a pesquisa. Posteriormente, apresentaremos episódios extraídos das açóes dos acadêmicos, onde encontramos indícios reveladores de aprendizagem da docência. Finalizando, traçaremos algumas consideraçóes acerca do estudo, orientadas principalmente por dois aspectos observados nos episódios: a necessidade dos futuros professores de estudar sobre o conteúdo a ser ensinado e o sentido atribuído por eles a essa açáo.

\section{Os pressupostos teóricos norteadores da pesquisa}

Os fundamentos teóricos deste trabalho partem dos princípios da Teoria Histórico-Cultural, em especial, da ideia de que o homem se desenvolve e se torna humano por meio das suas relaçóes sociais com outros indivíduos e com o mundo exterior, decorrentes de um processo histórico. A partir de Vigotsky maior expoente dessa teoria - e seus colaboradores, entendemos que estar e viver em sociedade são necessidades específicas do ser humano nos sentidos biológico, histórico e cultural, pois, além de um ser social, o homem é um ser natural, que também é conduzido por leis biológicas. Tal como qualquer animal, o homem atende às suas necessidades orgânicas e vitais, mas, além disso, ele procura atender às condições para o bem viver.

As necessidades humanas podem ser satisfeitas por meio de uma açáo intencional: o trabalho. Os pressupostos da Teoria Histórico-Cultural, que se fundamentam na perspectiva materialista histórico-dialética, destacam o trabalho como um alicerce para a construção e o desenvolvimento de qualquer sociedade, 
o elemento essencial na humanizaçáo de qualquer indivíduo e entendido como uma atividade humana orientada por objetivos para chegar a um determinado fim. Compreendemos, então, assim como Moretti (2007, p.101), que,

[...] se, dentro da perspectiva histórico-cultural, o homem se constitui pelo trabalho, entendendo este como uma atividade humana adequada a um fim e orientada por objetivos, então o professor constitui-se professor pelo seu trabalho - a atividade de ensino - ou seja, o professor constitui-se professor na atividade de ensino.

Assim como nossa preocupação está na aprendizagem da docência do futuro professor, olhar para a organização da sua atividade (de ensino) tornase importante para compreender o seu movimento de formação. E, ao pensar no desenvolvimento e na constituição do professor, apoiamo-nos em Vigotsky (1994), para quem o ser humano desenvolve suas funçôes psicológicas superiores por intermédio das relaçóes com outros indivíduos de sua espécie; e em Leontiev (1978), que afirma não ser suficiente o que a natureza proporciona ao ser humano no seu nascimento para ele viver em sociedade; é preciso que cada indivíduo aprenda a ser homem. Para isso, é necessário que ele se aproprie do que foi construído e desenvolvido historicamente pela humanidade. Ou seja, o homem não nasce dotado das aquisiçóes históricas da sociedade humana, mas deve apropriar-se delas durante a sua vida para adquirir as propriedades e as faculdades verdadeiramente humanas. Toda a bagagem histórica e cultural elaborada pela humanidade somente se mantém viva por meio da sua transmissão e da apropriação pelas geraçóes posteriores, em um processo de comunicação e interação social, no qual a educação escolar tem um papel preponderante.

A apropriação da cultura pelas geraçóes é possível a partir do desenvolvimento das funçôes psicológicas superiores, especificamente humanas, mediatizadas e produzidas nas relaçóes interpessoais e históricas do homem com a cultura. Vigotsky (1994) refere-se às ferramentas psicológicas que, diferentemente das ferramentas materiais (condutoras das influências humanas sobre objetos de atividade ferramentas externamente orientadas), são internamente orientadas e transformam habilidades e competências humanas naturais em funçôes psicológicas superiores.

Nesse contexto, uma fonte propulsora e condição necessária para o desenvolvimento do homem, com suas funçóes psicológicas superiores, é a aprendizagem. Ambos - desenvolvimento e aprendizagem - não se acompanham de forma paralela, não se realizam em igual medida; e, como aponta Vigotsky (2001), a aprendizagem não é seguida pelo desenvolvimento, como a sombra segue o objeto que a projeta. 
Compreendemos, assim, que a diferença essencial entre o homem e os demais animais reside na aprendizagem com o indivíduo mais experiente, no desenvolvimento das funções psicológicas superiores (percepção, memorização, atenção, pensamento e imaginação) e no desenvolvimento de atividades (processo realizado a partir de uma necessidade particular do homem). Mas é importante ressaltar que, de acordo com nossa perspectiva teórica, nem toda ação que o indivíduo realiza se constitui como uma atividade de fato, pois se ela não estiver atendendo a uma necessidade particular do indivíduo, é considerada apenas uma ação ou tarefa. Caso não existam motivos e necessidades, também não haverá atividade. Portanto, a atividade constitui-se como tal mediante alguns elementos relacionados de forma específica, entre eles: motivos, necessidades, objetos, objetivos, açóes e operaçóes (LEONTIEV, 1978). O que dá origem à atividade é a manifestaçáo de uma necessidade, que irá estabelecer as suas metas. O motivo, diferente da necessidade, é o que dirige a atividade, o que a estimula e impulsiona.

Outro aspecto relevante apresentado nessa teoria refere-se aos sentidos atribuídos pelos sujeitos a objetos, ações, etc. "O sentido é sempre uma formação dinâmica, fluida, complexa, que tem várias zonas de estabilidade variada." (VIGOTSKY, 2000, p. 465). O sentido de um objeto ou palavra é inesgotável; modifica-se de acordo com as vivências e a experiência do sujeito, traduzindo a sua relação com o objeto em questão por meio da sua definição pessoal. Em nosso trabalho, a compreensáo dos sentidos atribuídos pelos acadêmicos às açóes desenvolvidas faz-se importante, na medida em que podem tornar-se indicativos de sua aprendizagem quanto à organização do ensino.

Desse modo, tendo como suporte a Teoria Histórico-Cultural, compreendemos que os conhecimentos, dentre eles, o matemático, fazem parte da cultura humana e são construídos a partir das relaçóes sociais estabelecidas durante a sua história. Disso decorre o entendimento de que a Matemática se constitui como um conhecimento organizado e construído pela humanidade ao longo do tempo, com a finalidade de atender e satisfazer às necessidades que surgiram em determinado contexto e época histórica.

Como um produto de necessidades humanas, a Matemática insere-se no conjunto de elementos culturais que devem ser socializados, de modo a permitir a interação entre os sujeitos e possibilitar seu pleno desenvolvimento como homens. Assim sendo, os conhecimentos matemáticos podem contribuir de forma significativa para os alunos, pois, quando eles se envolvem em resolver os desafios que se apresentam nas atividades propostas na escola pelo professor, estáo se apropriando dos conhecimentos presentes nessa atividade, levando a novas aprendizagens que contribuem para o seu desenvolvimento. 
Nesse movimento, damos especial atenção para o papel do professor, ao organizar o ensino. $\mathrm{O}$ modo como irá desenvolver sua prática vai constituindose ao longo de sua história e pode ser modificado a partir de processos que lhe possibilitem aprender a ser professor. Para além de cursos de formação inicial e continuada, o professor também aprende a partir da sua relação com o mundo, com os colegas e com seus alunos. E aprende no seu trabalho, na sua atividade de ensino.

Nessa perspectiva, entendendo o papel do professor no processo de ensino e aprendizagem, Moura $(1996,2001)$ propóe a Atividade Orientadora de Ensino (AOE) como um modo geral de organização do ensino, que possibilita a aprendizagem para alunos e professores. O termo Atividade Orientadora de Ensino designa uma atividade organizada intencionalmente, capaz de desencadear no aluno um conjunto de açóes que visam à solução coletiva de uma situaçãoproblema cujo objetivo é levar o sujeito à aprendizagem de um novo conceito. Para Moura (2001, p.155), ela

[...] se estrutura de modo a permitir que sujeitos interajam, mediados por um conteúdo, negociando significados, com o objetivo de solucionar coletivamente, uma situaçáoproblema. [...] a Atividade Orientadora de Ensino tem uma necessidade: ensinar; tem açôes: define o modo ou procedimentos de como colocar os conhecimentos em jogo no espaço educativo; e elege instrumentos auxiliares de ensino: os recursos metodológicos adequados a cada objetivo e ação (livro, giz, computador, ábaco, etc.). E por fim, os processos de análise e síntese, ao longo da atividade, são momentos de avaliação para quem ensina e aprende.

A AOE organiza-se de acordo com a estrutura da atividade proposta por Leontiev (1983) e, dessa forma, realiza-se por meio de finalidades - ensinar e aprender - e de ações que consideram as condiçóes objetivas da escola (MOURA et al., 2010). É, portanto, uma unidade de formação do professor e do estudante, em que a função do professor é planejar açóes que se convertam em atividades e possibilitem a apropriaçáo dos conhecimentos e das experiências históricoculturais. O elemento fundamental, nesse processo, é a sua intencionalidade na organização e na concretização dos objetivos sociais do currículo escolar. Desse modo, aprender a ser professor não é apenas aprender o conteúdo a ser trabalhado, mas também fazer com que os conteúdos estejam, de alguma forma, acessíveis aos alunos. Tal premissa se torna particularmente importante quando nos propomos a investigar, como nesta pesquisa, o processo de formação de futuros professores. 
Contudo, a quantidade de conhecimentos produzidos em toda a história da humanidade é imensa e continua aumentando, o que inviabiliza um processo de ensino que possa propiciar o contato do estudante com o todo acumulado. Moura et al. (2010) apontam como soluçáo ensinar ao aluno um modo de ação generalizado, para acesso, utilização e criação do conhecimento. Dessa maneira, respeitando as especificidades de cada indivíduo e a partir da mediação do professor, é possível proporcionar a relação entre o humano singular e o humano genérico no contexto educativo.

Como jáafirmamos, a AOE compõe-se como proposta teórico-metodológica. Do ponto de vista teórico, ampara-se na Teoria Histórico-Cultural e na Teoria da Atividade; e, do metodológico, traz indicativos de elementos importantes para a organização do ensino. Destacamos, para esta nossa discussão, três deles: a Síntese Histórica do Conceito; a Situação Desencadeadora de Aprendizagem; e a Síntese da Solução Coletiva. O primeiro refere-se à organização e à constituição lógico-histórica, por parte da humanidade, do conceito a ser trabalhado, cuja compreensão pelo professor é essencial para a organização do ensino. O segundo concretiza-se na apresentação de um Problema Desencadeador de Aprendizagem aos alunos, a partir de uma Situação Desencadeadora de Aprendizagem (SDA), que mobilizará a turma a interagir para chegar a um nível elaborado de compreensão do conceito em questão. Esse movimento tem o objetivo de oportunizar a apropriação do conhecimento pelos alunos, de forma que contemple a gênese do conceito trabalhado. $O$ terceiro diz respeito aos alunos, quando, coletivamente, encontram a solução correta para o problema proposto. Nesse momento, a mediação deve levar os estudantes a respostas que coincidam com aquelas que a humanidade, ao longo da história, instituiu como corretas. A solução será construída a partir das interações mediadas pelos conhecimentos compartilhados no espaço de aprendizagem.

$\mathrm{Na}$ especificidade deste artigo, optamos por nos deter no primeiro momento, a Síntese Histórica do Conceito: futuros professores estudaram e discutiram acerca do conteúdo de grandezas e medidas, definido para uma atividade de ensino de Matemática que iriam desenvolver com alunos de uma escola de Educaçáo Básica. Apenas estudar a história, ler e conhecer sobre fatos que aconteceram de forma ilustrativa não contribui para a apropriação dos conceitos matemáticos. Ao adotarmos a AOE como premissa teórica e metodológica, entendemos a necessidade de uma organização do ensino que leve em consideração o caminho lógico e histórico percorrido pela humanidade na criaçáo dos conceitos matemáticos - no nosso caso, relativos a grandezas e medidas - e que coloque o aluno num movimento que lhe permita apropriar-se da essência desse conhecimento. 
Destacamos estas palavras de Kopnin (1978, p. 183-184):

Por histórico subentende-se o processo de mudança do objeto, as etapas de seu surgimento e desenvolvimento. O histórico atua como objeto do pensamento, o reflexo do histórico, como conteúdo. O pensamento visa à reprodução do processo histórico real em toda a sua objetividade, complexidade e contrariedade. O lógico éo meio através do qual o pensamento realiza essa tarefa, mas é o reflexo do histórico em forma teórica, vale dizer, é a reprodução da essência do objeto e da história do seu desenvolvimento no sistema de abstraçóes.

Compreendemos, assim, que o lógico é reflexo do histórico, ambos interdependentes; e, da mesma maneira, o histórico necessita da forma lógica de desenvolvimento para interpretá-lo. Segundo o autor anteriormente referido, para a revelação da essência do objeto, faz-se necessária a reprodução do processo histórico real de seu desenvolvimento, e esse só é possível ao conhecermos, entâo, o cerne do objeto - nesse caso, o conhecimento matemático, constituindo, desse modo, um ciclo de interdependência. $\mathrm{O}$ estudo da história nessa perspectiva, faz-se, portanto, necessário para atingir um grau mais elevado de conhecimento do objeto em questáo.

Além da história do objeto, o lógico traz o reflexo da história do seu conhecimento. "A unidade entre o lógico e o histórico é premissa metodológica indispensável na solução dos problemas da inter-relaçáo do conhecimento e da estrutura do objeto e conhecimento da história e seu desenvolvimento." (KOPNIN, 1978, p. 186). Como ressalta o autor, a unidade entre o lógico e o histórico torna-se uma premissa necessária para a total compreensão do movimento do pensamento.

Apresentados os pressupostos teóricos e metodológicos que orientam nossas ações no lócus de pesquisa, na próxima seção traremos episódios que, constituídos a partir dos momentos de estudos dos futuros professores, nos permitam discutir sobre a sua aprendizagem.

\section{O movimento de estudar para planejar: possibilidades para a aprendizagem da docência}

Como já explicitado, ao nos propormos a discutir sobre a aprendizagem da docência de futuros professores, o fazemos acompanhando um projeto desenvolvido em parceria entre a nossa universidade e escolas da rede pública estadual de ensino do estado do Rio Grande do Sul. Desse projeto, fazem 
parte professores universitários; professores da Educação Básica; estudantes de pós-graduação e de graduação. Sua dinâmica acontece a partir de estudo, planejamento, desenvolvimento e avaliaçáo de atividades de ensino de Matemática realizadas semanalmente com alunos dos anos iniciais do Ensino Fundamental, no horário regular das aulas - o que é possível devido à dimensão colaborativa de envolvimento das professoras regentes das turmas.

Embora a maior parte das açóes seja realizada de forma compartilhada, com a participação de todos os integrantes, nosso foco estará nas açóes dos sete acadêmicos, futuros professores, estudantes dos cursos de licenciatura em Matemática e Pedagogia, durante toda a organizaçáo de uma atividade sobre grandezas e medidas para ser desenvolvida com alunos do terceiro ano do Ensino Fundamental.

Os dados da pesquisa foram coletados em 15 encontros $^{4}$ a partir de gravaçóes de áudio e vídeo e, para sua análise, utilizamos o conceito de episódios proposto por Moura (1992, 2000, 2004), na expectativa de que sejam reveladores sobre a natureza e a qualidade das açóes. Eles se compóem de "frases escritas ou faladas, gestos e açóes que constituem cenas que podem revelar interdependência entre os elementos de uma ação formadora" (MOURA, 2004, p. 276), podendo ser definidos como "aqueles momentos em que fica evidente uma situação de conflito que pode levar à aprendizagem do novo conceito" (MOURA, 1992, p.77).

Apresentaremos dois episódios em que identificamos indícios de aprendizagem da docência, extraídos dos dois primeiros encontros do grupo que se preparava para organizar a atividade, na etapa inicial, que denominamos de "estudo", e objetiva a discussão sobre o conteúdo matemático a ser trabalhado, visando à organizaçáo do ensino para os alunos dos anos iniciais. Compóe-se de açóes a partir de referências bibliográficas da Matemática e da história da Matemática, dos pressupostos da AOE, da Teoria da Atividade e da Teoria Histórico-Cultural. Também nos reportaremos a algumas falas extraídas do terceiro encontro.

4 Cada atividade de ensino desenvolvida neste projeto (que envolve estudo, planejamento, desenvolvimento e avaliação) tem duração variável e depende de aspectos como: conteúdo matemático envolvido, tipo de açóes planejadas, envolvimento dos alunos dos anos iniciais com os quais estamos trabalhando, entre outros. 


\section{Episódio 1 - A necessidade de estudar}

Este episódio desenvolveu-se no primeiro encontro e, como estávamos iniciando o trabalho, decidimos realizar com os acadêmicos uma Situaçáo Desencadeadora de Aprendizagem de uma atividade de ensino denominada Atividade da Rapunzel, já desenvolvida no ano anterior pelo mesmo grupo, com os alunos dos anos iniciais. $\mathrm{O}$ mesmo problema desencadeador apresentado às crianças daquela vez foi, agora, proposto para os acadêmicos. A SDA inicia com uma história virtual ${ }^{5}$, e o problema - que envolvia personagens da história consistia em descobrir por que o Gigante e os anóes, ao seguirem um certo mapa desenhado pela Bruxa, com indicações de medidas em passos, não conseguiram chegar ao local desejado, onde estava presa a personagem Rapunzel.

Cada um dos futuros professores resolveu individualmente o problema proposto e leu sua resposta. A partir disso, tiveram início a discussão e a reflexão sobre a atividade, que podemos acompanhar a seguir ${ }^{6}$ :

1.1. Pesquisadora: Pensando nessa atividade [da Rapunzel], qual o conceito que está nela, qual o conceito que as crianças aprenderam, se apropriaram, a partir desta atividade?

1.2. Todos: Unidade de comprimento, uma medida-padrão para a unidade de comprimento.

1.3. Orientadora: Mas nós não falamos de "metro" para as crianças. Só o problema desencadeador, da forma como foi encaminhado, não fala de metro. Vocês chegaram, na atividade, ao metro, mas como se chegou ao metro?

1.4. Pedro: Eu acho que, com essa atividade aqui, os alunos perceberam que existe uma necessidade de padronização, é isso, só isso.

1.5. Pesquisadora: Como um resultado posterior, surgiu o metro.

1.6. Orientadora: Então, será que podemos responder à pergunta: "Por que surgiu o metro?"

5 A história virtual é aqui compreendida como uma narrativa que proporciona ao estudante a possibilidade de envolver-se na soluçáo de um problema coletivo, tendo como finalidade a satisfaçáo de uma determinada necessidade, semelhante ao que pode ter acontecido em certo momento histórico com a humanidade (MOURA et al., 2010). Ou seja, é um dos modos que utilizamos para apresentar para as crianças um problema desencadeador de aprendizagem.

6 Os acadêmicos que participaram da pesquisa escolheram nomes fictícios para manter o anonimato. Ao aceitarem participar da pesquisa, eles assinaram o Termo de Consentimento Livre e Esclarecido, atendendo às orientaçóes do Comitê de Ética em Pesquisa da nossa instituição. 
1.7. Pedro: Como a resposta de uma necessidade.

1.8. Sabrina: Essa atividade foi a introdução do trabalho com essa unidade, porque a gente falou do metro, mas depois de toda essa introdução.

1.9. Pesquisadora: Mas quando ele criou o metro, quando sentiu a necessidade de padronizar as medidas? O homem já media antes disso, mas por que ele media? Por que o homem começou a medir?

1.10. Pedro: Ao se pensar nas civilizaçóes antigas, a necessidade de medir estava na delimitação de terras, mas isso ao pensar a partir do momento que o homem se torna nômade e começa a se constituir como sociedade [...] mas, ao se pensar antes disso, se o homem já media antes disso, se já sentia a necessidade antes disso...

1.11. Sabrina: Ele utilizava as partes do corpo antes também.

1.12. Orientadora: Mas por quê?? Por que o homem começou a medir?

1.13. Pesquisadora: Por que o primeiro homem ou os primeiros homens começaram a medir?

1.14. Sabrina: Porque ele sentiu a necessidade de medir.

1.15. Orientadora: Sentiram a necessidade por quê? Ou melhor, vou fazer outra pergunta: o que é medir? Aqui estamos falando sobre medida de comprimento, mas o que é medir?

1.16. Pedro: Medir é contar.

\subsection{Orientadora: Contar o quê?}

1.18. Pedro: É contar uma unidade estipulada para medida, porque para cada medida eu vou ter uma unidade estipulada; por exemplo, não vou contar horas em metro... medir é contar uma unidade que foi estipulada, convencionada historicamente.

1.19. Orientadora: $N a$ verdade, não estou dizendo que é certo nem errado, só quero que pensemos sobre isso.

1.20. Pesquisadora: De que forma podemos ter certeza se isto está correto, porque não podemos simplesmente afirmar uma informação. Você pode afirmar que medir é isso?

1.21. Pedro: Eu só acho que é.

1.22. Pesquisadora: E como verificamos se é isso mesmo? Como podemos verificar a definição de medir, grandeza, medida? 
1.23. Orientadora: Vocês já falaram que são padróes, se são padróes alguém estabeleceu, como a gente vai saber que o padrão é esse?

1.24. Pesquisadora: De que forma a gente conhece esses padróes?

\subsection{Beatriz: Através do estudo.}

1.26. Orientadora: Porque, se eles são padröes, alguém estabeleceu. Então, se são padrôes e foram estabelecidos por alguém, esse alguém é o sujeito humano... se o homem fez, o fez a partir das necessidades, e se alguém fez, uma determinada sociedade fez. Como a gente sabe que isso é dessa forma, hoje?

[...]

1.27. Beatriz: Temos que estudar, buscar referenciais teóricos... sobre os padröes criados pelo homem.

Nesse episódio, tentamos desenvolver uma atividade na perspectiva da AOE com os acadêmicos, buscando avaliá-la para pensar numa nova proposta a ser elaborada. $\mathrm{O}$ intuito era refletirmos se aquela atividade tinha realmente atendido ao objetivo de levar os alunos dos anos iniciais a apropriarem-se do movimento do surgimento da necessidade de medir. Nas primeiras discussóes, os acadêmicos atentaram para o fato de que replanejar uma atividade de ensino sobre os conceitos iniciais referentes ao que queríamos trabalhar envolveria, necessariamente, o estudo mais aprofundado sobre o tema, a constituição histórica dos conceitos e suas definiçóes e propriedades matemáticas.

Em sequência às falas apresentadas, ocorreu mais um momento de discussóes, em que o desencadeamento do diálogo nos possibilitou apontar algumas consideraçóes acerca das necessidades que ficaram evidentes na resolução do problema e nos motivos que mobilizaram os futuros professores. Ao discutirem sobre a Atividade da Rapunzel e os conteúdos matemáticos que ela envolveu, constataram uma falha: a atividade náo enfatizava a necessidade do ato de medir - partia direto para a padronização das unidades. Com essa nova ideia, até então não abordada no grupo, os acadêmicos, em suas falas, atentaram, de uma forma geral, para o fato de que não possuíam subsídios teóricos para elaborar e desenvolver uma atividade. E isso os levou à ação seguinte - estudar sobre grandezas e medidas.

Chamamos a atenção para o fato de que essa ação de estudar estava relacionada à organização do ensino e, sendo assim, em relação intrínseca com a aprendizagem para a docência. Sobre o professor em formação inicial, fica claro na afirmação de Lopes (2009, p.178) que 
[...] a constatação da necessidade de buscar conhecimentos, no sentido de aprender para ensinar, pode constituir-se como aprendizagem na medida em que o futuro professor toma consciência da importância de assumir a formação como um processo dinâmico, em constante reelaboração.

Desse modo, a conclusão, pelos estudantes, de que se fazia necessário um estudo para organizar o seu ensino pode indicar que suas preocupaçóes se direcionem ao fato de tornar-se professor, pois visavam à aprendizagem por parte dos seus alunos. O que podemos observar, assim, é a existência de um motivo que mobilizou os estudantes a uma direção concreta: a elaboração da atividade de ensino. Ao destacar, especialmente na fala 25 , de Beatriz, que só "tomamos conhecimento das informaçôes imprescindiveis para o planejamento da escola através do estudo", percebemos que os motivos que impulsionaram e orientaram as açóes de estudo dos acadêmicos podem ser considerados geradores de sentido, na medida em que, ao estimular a atividade, conferiram-lhe sentidos pessoais (dos futuros professores) acerca da importância e da necessidade do estudo. E, além de buscar o aprendizado individual, todos tinham como intuito estudar e planejar coletivamente uma atividade que se adequasse às características da AOE.

Assim, evidenciamos a relaçáo entre os motivos dos estudantes e as necessidades que surgiram para o estudo. Podemos identificar que, a partir da necessidade de apropriar-se de conhecimentos para poder organizar o ensino, o motivo que os levou a estudar coincide com o objeto da atividade de estudar, que é apropriar-se do conteúdo. Isso nos leva a inferir que o estudo desenvolvido posteriormente pelos futuros professores pode ter-se constituído como uma atividade de aprendizagem, na perspectiva dos pressupostos que aqui adotamos.

\section{Episódio 2 - Onde buscar subsídios teóricos para o estudo}

No episódio apresentado anteriormente, os acadêmicos concluíram que, durante a Atividade da Rapunzel, foi destacada apenas a padronizaçáo de unidades de medida para comprimento, pois somente após o estabelecimento de uma unidade como padrão social foi instituído o metro. Entretanto, quando isso aconteceu, o homem já sabia medir. A partir disso, foram discutidos com o grupo vários aspectos: como o homem media antigamente, o que é medir, o que podemos medir, como conhecemos as mediçóes realizadas pelo homem ao longo da história. A reflexão dos acadêmicos possibilitou compreender que temos acesso aos conhecimentos por meio dos registros de épocas e sociedades passadas. 
No segundo encontro, retomamos as discussóes anteriores e propusemos uma nova pergunta: "Como fazemos para resgatar e conhecer os registros?"

2.1. Orientadora: Como fazemos para resgatar os registros?

2.2. Sabrina: Estudando, vivenciando, através da sintese histórica, é o que a gente tenta fazer; primeiro a gente faz um estudo teórico para ver como que a bumanidade foi se apropriando, depois faz uma tentativa de tentar fazer com que as crianças experienciem isso [...] pra ir se apropriando desse processo.

2.3. Branca: A gente usa e vai se apropriando de outras ideias já existentes, vai modificando conforme as nossas necessidades também.

$[\ldots]$

2.4. Orientadora: $O$ que seria esse estudo teórico em Matemática?

2.5. Branca: Como surgiu a necessidade do conteúdo, no caso da medida, qual foi a necessidade que o homem sentiu de medir.

2.6. Pedro: É importante este estudo da gênese do conceito [...] mas, num segundo momento, o estudo do conteúdo em si [...], o modo como eu vou abordar esse conteúdo com os alunos, a linguagem que eu vou usar pra ser uma linguagem que o aluno entenda, mas que não fuja da linguagem matemática [...]

2.7. Pesquisadora: Da forma como fizemos o estudo na [atividade] da Rapunzel, vocês acham que contemplou essa parte histórica e do conteúdo matemático?

2.8. Orientadora: $A$ necessidade de medir ficou respondida através desse problema desencadeador?

2.9. Pedro: Foi introduzida, eu acho.

2.10. Pesquisadora: Qual foi o conceito que a gente trabalhou nessa atividade?

2.11. Todos: Padronização.

2.12. Orientadora: E a necessidade de medida? Nós trabalhamos aqui?

2.13. Caroline: Se nem a gente sabe responder agora, acho que muito menos as crianças conseguiräo isso.

2.14. Orientadora: Será que não está faltando isso, quando a gente pensar em medidas?

2.15. Pesquisadora: Temos subsidios, condiçôes de responder agora qual foi essa necessidade do homem de medir?

2.16. Branca: Não. (Os outros concordam) 
2.17. Pesquisadora: E o que a gente pode fazer para atender essa necessidade nossa?

2.18. Beatriz: Estudar.

2.19. Pesquisadora: Boa ideia, mas de que forma a gente pode estudar?

2.20. Orientadora: Podemos, então, pegar um livro de Matemática do $5 .^{\circ}$ ano?

2.21. Pedro: Pra esse momento, não.

2.22. Pesquisadora: A gente vai encontrar essa resposta em um livro didático?

2.23. Branca: Não.

2.24. Pedro: $O$ que a gente tá procurando não, pra esse momento de estudo, não.

2.25. Pesquisadora: $O$ que a gente tem que procurar?

2.26. Pedro: Fontes que tragam essa retomada histórica.

Nesse episódio, ficaram evidentes as ações que o grupo apontou como solução para ter condiçóes de planejar novamente uma atividade sobre o conteúdo de grandezas e medidas. E, após esse encontro, um primeiro passo partiu dos estudantes: a realização de um estudo para subsidiar a elaboração de uma atividade que evidenciasse a necessidade de medir esse estudo, relacionado aos aspectos lógico e histórico do surgimento e sistematização do conceito de medir e também à melhor forma de trabalhá-los com as crianças.

A partir dessa etapa de encaminhamento das açóes, mais especificamente do diálogo anteriormente relatado, podemos assinalar algumas consideraçóes que julgamos relevantes.

Em relação ao conhecimento que o professor precisa ter para ensinar, as falas da acadêmica Sabrina, na linha 2, e da acadêmica Caroline, na linha 13, enfatizam a importância de o professor ter experiências e apropriar-se do conceito matemático, para, somente depois disso, ter condiçóes de desenvolver atividades em que os alunos também passem por esse processo de construção. Esse movimento de apropriaçáo do conhecimento, ao ser assumido como um elemento importante para o planejamento das aulas, pode promover a aprendizagem da docência e o desenvolvimento do sujeito. Moura et al. (2010, p. 90) afirmam que

[...] o professor que se coloca, assim, em atividade de ensino continua se apropriando de conhecimentos teóricos que lhe permitem organizar açóes que possibilitem ao estudante a apropriaçáo de conhecimentos teóricos explicativos da realidade e o desenvolvimento do seu pensamento teórico, ou seja, açóes que promovam a atividade de aprendizagem de seus estudantes. 
Sobre o estudo do professor, as falas dos estudantes, em especial nas linhas 2, 6, e 18, indicam a importância que os acadêmicos dedicam ao fato de o professor estudar e aprender para ensinar, ou seja, no momento em que desenvolve uma atividade de ensino, ela pode se converter também em atividade de aprendizagem para o professor. Mas, para que a ação de estudar se converta em atividade, é preciso que tenha origem em uma necessidade e que seu motivo coincida com o objeto. De acordo com Leontiev (1978, p.107-108),

[...] toda atividade é dirigida por um motivo que procura atender às necessidades do sujeito. Uma necessidade só pode ser satisfeita quando encontra um objeto, ou seja, um motivo. O motivo é o que impulsiona uma atividade, pois articula uma necessidade a um objeto. Objetos e necessidades isolados não produzem atividade, a atividade só existe se há um motivo.

Logo, ao estudar para planejar a atividade, os acadêmicos não poderiam estar preocupados em simplesmente ler um texto para cumprir uma tarefa proposta pelo grupo. Ao contrário, assim como o indicativo de estudar partiu deles, esse movimento, como já constatado anteriormente, esteve motivado pela necessidade de aprender sobre o assunto, coincidindo com o objeto - apropriar-se dos conteúdos envolvidos - e, como consequência, conseguir planejar a atividade. Ou seja, a atividade de aprendizagem subsidiou a atividade de ensino, na medida em que a apropriaçáo do conhecimento matemático por parte dos futuros professores permitiu a posterior organização de uma Situação Desencadeadora de Aprendizagem, visando à apropriação dos conceitos pelas crianças. Acreditamos que é nessa perspectiva que a AOE pode constituir-se como unidade formadora do professor e do aluno.

\section{Considerações sobre a aprendizagem dos futuros professores}

Buscando contemplar o objetivo inicialmente proposto de discutir a aprendizagem da docência de futuros professores, pautados nos pressupostos teóricos já explicitados, apontamos dois aspectos que evidenciamos e que orientaráo as consideraçóes que teceremos a partir dos episódios apresentados. Tais aspectos entrelaçam-se e dizem respeito à necessidade dos futuros professores de estudar sobre o conteúdo a ser ensinado e o sentido atribuído por eles a essa ação.

No decorrer dos diálogos dos dois episódios, as discussóes levaram os acadêmicos a concluir sobre a importância de estudar para apropriar-se do conhecimento matemático que iriam ensinar, atribuindo-lhe um caráter de 
pressuposto para planejar. Ou seja, o motivo deu um novo sentido ao estudar, agora, relacionado à organizaçáo do ensino.

Ao produzir novos motivos no decorrer da própria atividade o professor também passa a atribuir novos sentidos a ela, o que inclui novos sentidos às suas açôes, aos instrumentos que escolher e ao processo de trabalho coletivo que criou condiçôes para as mudanças percebidas. (MORETTI, 2007, p. 121).

Sobre os motivos, Leontiev (1978) apresenta dois tipos: os motivos apenas compreensíveis e os motivos realmente eficazes, geradores de sentido. O motivo é compreensível quando é externo à atividade do sujeito, funciona como um estímulo e é apenas compreendido pelo sujeito. Porém, os motivos são eficazes na medida em que geram um sentido pessoal ao sujeito em atividade. Nessa perspectiva, Leontiev destaca e aprecia o papel da escola e do professor na transformaçáo de motivos e no desenvolvimento psíquico.

Muitas atividades podem ter, inicialmente, motivos apenas compreensíveis. Entretanto, a partir dos resultados das suas açôes, vão se tornando motivos eficazes. No nosso trabalho, nas reflexóes sobre a SDA da Atividade Rapunzel, foi possível observar três pontos em que houve mudança a partir de motivos geradores de sentido e atribuição de novos sentidos pelos acadêmicos: a compreensão de que, ao trabalhar com grandezas e medidas, a primeira SDA a ser proposta deve ser sobre o conceito de medir; a percepção de que o estudo para a atividade realizada anteriormente não havia sido suficiente; e a conclusão de que não é qualquer referencial teórico que lhes pode subsidiar o estudo e permitir a apropriaçáo da essência do conceito a ser trabalhado.

Ainda ao discutir sobre a SDA da Atividade da Rapunzel, nos dois episódios, a ação de estudar, decorrente das reflexóes, ficou bem marcada como oriunda de uma necessidade explicitada nas falas dos acadêmicos em vários momentos: a apropriação de conhecimentos para organizar o ensino.

A partir disso, é possível dizer que o conhecimento a que se referem os acadêmicos diz respeito tanto ao conceito matemático em questáo quanto aos aspectos relevantes para a efetivaçáo de um trabalho pedagógico que leve os alunos a aprender. Portanto, a necessidade de estudar e organizar o estudo também reflete no grupo a "necessidade de criar situaçóes que permitam aos sujeitos estabelecerem apropriaçóes das objetivaçóes humanas produzidas historicamente." (MORETTI, 2007, p. 48). Acreditamos que os indivíduos possam interagir e apropriar-se da cultura elaborada pelo homem em diferentes contextos e, por isso, concordamos com Moura (2001) quando aponta que é no processo de educação escolar que acontece a apropriação de conhecimentos ligados à intencionalidade social. 
Sobre a apropriação e a apresentação do conhecimento matemático nas ações dos acadêmicos, em especial nas falas relatadas nos episódios, eles próprios indicam que a sua bagagem de estudos matemáticos é insuficiente para bem desempenhar o papel de professores. Essa Matemática é oriunda da sua formação, seja na Educação Básica ou na formação inicial como educadores, e mostra-se deficitária, ao pensar em como ensiná-la para as crianças. E isso fica evidente tanto nos alunos da Licenciatura em Matemática quanto nos da Pedagogia. A possibilidade de integrar um grupo de estudos e pesquisas que se volte para essas preocupaçóes é uma oportunidade de refletir sobre essas dificuldades, embora tal processo de estudo, discussão e organizaçáo do ensino possa consolidar-se como recorrente na sua prática.

A prática do estudo coletivo faz parte da dinâmica do nosso grupo, de modo que o planejamento das atividades também acontece de forma compartilhada e intencional a partir desse estudo. O referido pressuposto decorre da ideia de Vigotsky (1994) de que as funçóes psicológicas superiores se desenvolvem a partir das relaçóes sociais que o indivíduo estabelece com o mundo. Ou seja, resultam da relação entre as pessoas, para depois serem interiorizadas. Assim, acreditamos que esse movimento favoreça o desenvolvimento e a aprendizagem da docência de cada indivíduo, como parte de um grupo que possui as mesmas preocupaçóes e os mesmos interesses. Apontamos a importância de que essa prática de organização do ensino compartilhada ocorra em todos os espaços escolares, conforme Moura (2001, p. 157) discute:

As atividades de ensino, portanto, deveriam ser fruto de acordos coletivos sobre os fins da educaçáo que se quer. A intencionalidade educativa é, no seu nascedouro, o resultado de múltiplos fatores que se unem num propósito coletivo de querer influenciar ou modificar comportamentos. E esta modificação por sua vez poderá servir para alterar algum aspecto da realidade, graças à aprendizagem sobre como realizar açóes concretas, tais como: construir uma ferramenta, realizar uma intervenção cirúrgica ou construir estradas. $\mathrm{Ou}$ seja, as intencionalidades educativas proporcionaráo mudanças em sujeitos que adquirem novas competências, comportamentos e valores e, na realidade objetiva, como resultado das açôes desses sujeitos.

Todavia, para organizar o ensino de forma coletiva, na perspectiva apontada, levantamos uma outra questão: qual é o conhecimento matemático que o professor precisa para organizar e desenvolver seu trabalho? As falas dos acadêmicos indicam que eles esperam realizar um estudo que lhes permita compreender a essência dos conceitos que irão trabalhar com as crianças. Entretanto, o enfoque do conteúdo descontextualizado do seu movimento lógico-histórico ou ainda o simples relato 
de um fato histórico não será suficiente para essa aprendizagem. É necessário um estudo que permita compreender a relação entre o lógico e o histórico do conceito. O histórico corresponde ao processo com as etapas de surgimento e desenvolvimento do conhecimento matemático, enquanto o lógico representa "o estudo da estrutura, dos meios de demonstração, do surgimento e evolução de uma teoria científica" (KOPNIN, 1978, p.21) - de certa forma, uma apropriação dos aspectos históricos pelo pensamento do homem.

\begin{abstract}
À base do conhecimento da dialética do histórico e do lógico resolve-se o problema da correlaçáo entre o pensamento individual e o social; em seu desenvolvimento intelectual individual o homem repete em forma resumida toda a história do pensamento humano. (KOPNIN, 1978, p. 186).
\end{abstract}

No dizer do autor já referido, "para revelar a essência do objeto é necessário reproduzir o processo histórico real de seu desenvolvimento, mas este é possível somente se conhecemos a essência do objeto." (KOPNIN, 1978, p.184). Assim sendo, a compreensão do processo lógico-histórico do conceito é importante ao desenvolvermos um trabalho pedagógico fundamentado na THC, em que a lógica do conceito e a sua construçáo humana histórica caminham juntas.

Por fim, destacamos que, no processo de organização do ensino, a necessidade de elaborar as açôes a serem desenvolvidas pelos alunos pode mobilizar a aprendizagem da docência a partir da apropriaçáo de novos conhecimentos relativos aos conteúdos e aos conceitos que serão trabalhados em sala de aula. Dessa forma, os conhecimentos matemáticos adquiridos pelos acadêmicos e utilizados durante suas açóes, a partir da dinâmica do grupo, permitiram a organização e o desenvolvimento da prática pedagógica na escola. Para além disso, consideramos que lhes permitiram também construir um modo geral de organizaçáo do ensino que poderá ser utilizado em outros momentos, na solução de problemas e em novas atividades escolares.

\title{
Referências
}

D'AMBROSIO, U. Da realidade à ação: reflexôes sobre educação e matemática. São Paulo: Summus, 1986.

KOPNIN, P. V. A dialética como lógica e teoria do conhecimento. Rio de Janeiro: Civilização Brasileira, 1978.

LEONTIEV, A. N. O desenvolvimento do psiquismo. São Paulo: Moraes, 1978. 
Actividad, consciência, personalidad. 2. ed. Habana: Pueblo y Educación, 1983.

LOPES, A. R. L. V. Aprendizagem da docência em matemática: o Clube de Matemática como espaço de formação inicial de professores. Passo Fundo: Ed. Universidade de Passo Fundo, 2009.

MORETTI, V. D. Professores de Matemática em atividade de ensino: uma perspectiva histórico-cultural para a formação docente. 2007. Tese (Doutorado em Educação) - Faculdade de Educação da Universidade de São Paulo, São Paulo, 2007.

MOURA, M. O. de. Construçáo do signo numérico em situaçáo de ensino. Tese (Doutorado em Educação) - Faculdade de Educação, Universidade de São Paulo, São Paulo, 1992.

A atividade de ensino como unidade formadora. Bolema, Rio Claro, v. 12, p.29-43, 1996.

O educador matemático na coletividade de formaçáo: uma experiência com a escola pública. Tese (Livre-Docência) - Faculdade de Educação, Universidade de São Paulo, São Paulo, 2000.

A atividade de ensino como açáo formadora. In: CASTRO, A. D. de; CARVALHO, A. M. P. de (Org.). Ensinar a ensinar: didática para a escola fundamental e média. São Paulo: Pioneira Thompson Learning, 2001. p. 143-162.

Pesquisa colaborativa: um foco na açáo formadora. In: BARBOSA, R. L. L. (Org.) Trajetórias e perspectivas da formação de educadores. São Paulo: Editora Unesp, 2004. Cap. 18, p. 257-284.

MOURA, M. O. et al. A atividade orientadora de ensino como unidade entre ensino e aprendizagem. In: MOURA, M. O. (Org.). A atividade pedagógica na teoria histórico-cultural. Brasília: Liber Livro, 2010.

VIGOTSKY, L. S. A formaçáo social da mente: o desenvolvimento dos processos psicológicos superiores. São Paulo: Martins Fontes, 1994.

Fontes, 2000.

A construçáo do pensamento e da linguagem. São Paulo: Martins . Uma contribuição à teoria de desenvolvimento da psique infantil. In: VIGOTSKII, L. S.; LURIA, A. R; LEONTIEV, A. N. Linguagem, desenvolvimento e aprendizagem. 2.ed. São Paulo: Ícone, 2001. p. 59-83.

Recebimento em: 09/08/2015.

Aceite em: 15/12/2015. 